Illinois State University

ISU ReD: Research and eData

Theses and Dissertations

$10-21-2014$

\title{
Operating An Interior Design Firm In Saudi Arabia:opportunities And Challenges For Professional Female Employees
}

Najah Alsaffaf

Illinois State University, najahalsaffaf@gmail.com

Follow this and additional works at: https://ir.library.illinoisstate.edu/etd

Part of the Entrepreneurial and Small Business Operations Commons, and the Graphic Design Commons

\section{Recommended Citation}

Alsaffaf, Najah, "Operating An Interior Design Firm In Saudi Arabia:opportunities And Challenges For Professional Female Employees" (2014). Theses and Dissertations. 280.

https://ir.library.illinoisstate.edu/etd/280

This Thesis is brought to you for free and open access by ISU ReD: Research and eData. It has been accepted for inclusion in Theses and Dissertations by an authorized administrator of ISU ReD: Research and eData. For more information, please contact ISUReD@ilstu.edu. 
OPERATING AN INTERIOR DESIGN FIRM IN SAUDI ARABIA: OPPORTUNITIES

AND CHALLENGES FOR PROFESSIONAL FEMALE EMPLOYEES

\author{
Najah Alsaffaf
}

56 Pages

December 2014

Empowering women is the aim of the research. Saudi Arabia is the research location and interior design is the subject of the investigation. Saudi Arabia is on the path of empowering women through education and facilitating job opportunities. There is vast research about entrepreneurship and obstacles that women face in Saudi Arabia, but there is no evidence of research on the interior design field in Saudi Arabia in both education and job opportunities. Finding out that the art and design scene is thriving in education indicates that there would be a need for creating jobs and employment options for design graduates. Also, the fact that the majority of art and design graduates are females supports the need for this research.

Seven interior design firms have been surveyed in order to document the current business operations of interior design firms in Saudi Arabia. The research is not just for the country's economic growth but also for the Saudi women self -dependency. Educated women regardless whether if their education was obtained locally of internationally should be confidant to apply and be part of the design scene. Experience and skill is vital because it is what firms look for when hiring designers. 
OPERATING AN INTERIOR DESIGN FIRM IN SAUDI ARABIA: OPPORTUNITIES AND CHALLENGES FOR PROFESSIONAL FEMALE EMPLOYEES

\author{
NAJAH ALSAFFAF
}

A Thesis Submitted in Partial Fulfillment of the Requirements for the Degree of

MASTER OF SCIENCE

Department of Family and Consumer Sciences

ILLINOIS STATE UNIVERSITY 


\section{(C) 2014 Najah Alsaffaf}


OPERATING AN INTERIOR DESIGN FIRM IN SAUDI ARABIA: OPPORTUNITIES AND CHALLENGES FOR PROFESSIONAL FEMALE EMPLOYEES

NAJAH ALSAFFAF

COMMITTEE MEMBERS:

Connie Dyar, Chair

Bill Anderson

Hae Jin Gam 


\section{ACKNOWLEDGMENTS}

I would like to thank everyone who was part of making this paper happen. To Connie Dyar, my mentor, thank you for all your time, encouragement and support. To Dr. Bill Anderson for believing in the issue I am trying to bring to light and support you have provided. To Dr. Hae Jin Gam for your guidance and contributing with your expertise. And last but not least, my dearest husband, Amr Awwad for being there for me every step of the way, you are the best. Thank you.

N.A. 


\section{CONTENTS}

Page

ACKNOWLEDGMENTS

CONTENTS

TABLES $\quad$ iv

CHAPTER

I. OPERATING AN INTERIOR DESIGN FIRM IN SAUDI ARABIA: OPPORTUNITIES AND CHALLENGES FOR PROFESSIONAL FEMALE EMPLOYEES

Introduction

Importance Of The Study

The Ninth Development Plan \& Theoretical

Perspectives

Research Methodology 9

Results And Discussion 12

Firm Location $\quad 12$

Demographic Questions $\quad 13$

Number Of Designers Working For The Design firm 14

Qualifications For The Hiring Process 16

Transportation 16

Segregation 18

Jobs, Technology And Skills 19

Conclusion $\quad 21$

References 23 
II. EXTENDED LITERATURE REVIEW 25

Introduction 25

The Ninth Development Plan And The Feminist Theory 27

Challenges That Women Face To Be Part Of The Workforce In

Saudi Arabia

Transportation Obstacles 32

Employment Options For Saudi Females $\quad 34$

Training And Support 35

Work Location $\quad 37$

Interior Design 38

Interior Design's Education And Profession In Saudi Arabia 38

Technology In The Interior Design Field $\quad 41$

Conclusion 45

References $\quad 47$

APPENDIX A: Informed Consent Form (Back Translated) (English) 50

APPENDIX B: Survey Questions (Survey Monkey Format) (Back Translated)

(English) 


\section{TABLES}

$\begin{array}{lll}\text { Table Page } & \end{array}$

1. Demographics Of Design Firm Participants 13

2. Number Of Designers Working For The Design Firm 15 


\section{CHAPTER I}

OPERATING AN INTERIOR DESIGN FIRM IN SAUDI ARABIA: OPPORTUNITIES AND CHALLENGES FOR PROFESSIONAL FEMALE EMPLOYEES

\section{Introduction}

How is Saudi Arabia different from any other country in the world, including middle eastern and gulf countries? Do women get what they deserve to live the life they ask for? These questions come to the minds of a lot of people who are unfamiliar with the country and its culture. Media plays a big role on their perception. Even though stereotypes exist everywhere, regardless of location in the world, the way people deal with it makes a difference. People in Saudi have been able to change how people view them because of changes it was facing with the education system and exposure to the outside world. Men and women have been able to reach their goals and be part of a better future of their careers due to the scholarship grants that the Government provides for its

citizens. Cultural exchange between Saudi students/scholars and their counter parts from all parts of the world have and will continue to provide an important platform of understanding and tolerance. It's true when given a chance and the means to succeed in life one can make a big difference. 
A brief explanation of Saudi's culture and governance will give a great overview of why people would believe that Saudi is different, and the various stereotypes that exist and affect both men and women in the society. Not specifically in a negative way, but on the contrary in a very positive way.

There are realities that shape the Kingdom of Saudi Arabia and differentiate it from other countries in the world, and even surprisingly from the rest of the Middle Eastern and gulf countries. As Aldraehim (2013) explains, "Islam is the first element of Saudi Arabia's culture and sets the moral principles and behaviors in its society through the Koran (the holy book) and the Sunna (the sayings and practices of the prophet Mohammed peace be upon him), which is in brief the country's constitution." There are various limitations that the Saudi people face and particularly women. Segregation, ban on women driving, inadequate job opportunities, and lack of training in various fields of education are some of the obstacles women face. Many outsiders who look at Saudi Arabia have the misconceived notion that the difficulties women face make it challenging for women to have an easy and convenient life, but is this is really the case?

As Inglehart \& Norris (2004) mention, Western activists believe that moving toward achieving equality, in the home, in the workplace, and in positions of education, health and political power, remains one of the most important challenges facing the Saudi government in the twenty-first century (as cited in Alsaleh, 2012, p. 123). The challenge of creating equality in the Saudi culture makes the study of women's needs and finding a niche market where they could thrive and bloom is an area worthy of investigating. Finding out that there is a current support for women's education and validation for their need in boosting the economy could be the positive element for women to achieve career 
and job goals. Digging deeper and discovering that the art and design domains are making a big mark in the Saudi scene is a great encouragement to find ways to make these fields of study beneficial for the country in general and its female population in particular.

The primary research questions that guided the research are:

RQ1: How are employees, in particular females, in Saudi Arabia able to obtain appropriate training that provides them with the uncategorized skills, in agreement with the Ninth Development Plan, needed to work in the interior design profession?

RQ2: How is communication between males and females work sections facilitated within a stratified work environment and use of technology? Does the work environment actually suggest stratification and/or privilege?

RQ3: What technologies and software can best be adapted in a firm to complete interior design projects?

The paper proceeds by introducing a crucial topic of the Ninth development plan and its relation to the theoretical perspectives that support it and highlights the importance of the study. Then, relevant literature is presented in the context of Saudi Arabia. It then explains the methodology used to conduct the research. The research started with finding 19 interior design firms that were approached with a survey sent via 
email requesting their participation in the study. The total number of participants who completed the survey is 7 .

In particular, the purpose of this study is to document the current business operations of interior design firms in Saudi Arabia. Also, to explore how the current support for the education of Saudi females can be translated into employment and training within the profession and realm of interior design.

\section{Importance Of The Study}

\section{The Ninth Development Plan \& Theoretical Perspectives}

Now in the $21^{\text {st }}$ century, with all the new advancements in Saudi Arabia there is easy access to the outside world through technology. Finding the balance between the culture and way of life in modern Saudi is the challenge that some women face to become successful and be part of society to the fullest. The government plays a big role in finding a solution to women's obstacles. Women are a big part of the four-year developmental plans of Saudi Arabia, and most recently in the Ninth Development Plan which spans from 2010-2014 issued by the Ministry of Economy and Planning. As defined by the ministry of Economy and Planning (2010, p.7), "The Ninth Development Plan is a continuation of the developmental approach adopted by the Kingdom throughout the past four decades. This approach combines the directive planning of government activity and indicative planning of private activity within a framework of developmental paths and the future vision defined by the long-term strategic planning." 
When talking about social and cultural aspects, the association of these to the community as a whole and the wellbeing of a country's people is a must. A society cannot improve as a whole without looking deeper into its roots. In Saudi Arabia, women have been categorized as a marginalized group within the society because of reasons such as state rules and the segregation between men and women that has repercussions on attitudes, and the design of spaces (LeRenard, 2008). Feminist theory, which essentially focuses on changing the social experiences and understandings of women give women as a marginalized category great attention. Working in parallel with some of the goals of the Ninth Development Plans, the feminist theory seeks to illuminate status differences between genders so underrepresented populations can be empowered (Smith \& Hamon, 2012).

Some of the major themes that are integrated in the Ninth Developmental Plan address the economy of the Kingdom of Saudi Arabia by focusing on women and the family as a whole in the coming years. The following are the main headlines that mentions women as a minority group that should be given greater attention in the society (Ministry of Economy and Planning, 2010):

- “Enhancing and intensifying efforts to improve citizens standard of living and promote their quality of life"

- "Paying attention to the social dimension of the development through enhancing private participation in the process of development, social care, support of needy categories and groups with special needs, and giving special attention to youth, women and children" 
- "To support efforts to increase participation of the national workforce (males and females) in the labor market"

- “To promote the effective participation of Saudi women in the Kingdom's development"

There are various cultural issues that stand in the way of women reaching their goals. Feminist family theory states, stratified gender roles are a reason behind these obstacles (Smith \& Hamon, 2012). This theory supports the idea that society plays a big part in assigning roles to each gender. As a society that is significantly affected by its culture, Saudi citizens have labels automatically placed on them based on their sex, whether for occupational, economic, or status reasons.

The assignment of gender roles has been part of various societies not only in the kingdom but also around the world. White \& Klein (2008) state, "Gender structures all societies." Gender is used as a basic class distinction in all societies. It is a cultural symbol that helps construct social class. As Aldraehim (2013, p, 14) states, "a nation's culture in general involves the observation of rules, customs, responsibilities, and morals, which are influenced by language, gender dynamics, race, beliefs, geography, work and other factors. All of these aspects influence interpersonal needs." Interpersonal needs in this situation are the Saudi Arabian women's needs as they are the category in focus.

Research done by Aguirre, Hoteit, Rupp and Sabbagh (2012) has named all women in the world as the " Third Billion." They have statistical evidence that women are still not fully recognized in many countries and especially in the Middle East and the Gulf countries. The Third Billion have not received sufficient attention from governments, business leaders, or other key decision makers in many countries. The 
kingdom of Saudi Arabia is experiencing tremendous growth as the population has tripled over the last 30 years with a median age of 25.3 years (CIA, 2011). Within this population are women, who despite what people believe have an integral role to the overall growth of the kingdom. Through education and job opportunities, women can make a great difference in the overall economy of the country. However, work needs to be done to ensure women's full participation in the Saudi family, work place, and society.

In Saudi Arabia, education has been identified not only as a source for the empowerment of women but also as being vital to "the economic survival of the country in years to come" (Danish \& Smith, 2012). The large pool of educated women, whose talent remains largely untapped, will be crucial to this evolution. As Kaaki (2010) says, "Investment in girls education may well be the highest return investment available in the developing world"(as cited in Vaid, 2011,p.450). Education has been a segregated sector in Saudi Arabia since the 1960's and remains till now (LeRenard, 2008). This played a role in bringing women from different background to socialize under one roof and meet one another.

Saudi Arabia is ranked $123^{\text {rd }}$ among the countries who are "at the starting gate" of empowering women in the economy by providing more opportunities and realizing their value to the overall society (Aguirre, et. al. 2012). Even though women have cultural and religious barriers that prevent them sometimes from enrolling in higher education, the number of women receiving a higher education, whether in their home country or abroad has increased over the years because of the investment in the scholarship programs. Educated women are valuable assets to society. They represent 57 percent of university graduates in Saudi Arabia, but unfortunately are still under represented in the workforce. 
The unemployment rate for women is 28 percent, compared to 7 percent for men (Aguirre, et. al. 2012). Mena Gender Compendium (2009) explains, “Women's' function in the wider society is limited and Saudi Arabia has one of the lowest participation of women in the workplace, particularly graduates."

Al-Mohamed (2008) states that as the educational opportunities for women rapidly progresses an increase in the number of women in the work force should be the next step. Al-Mohamed also says, "Currently, roughly 300,000 Saudi women work, comprising five percent of the Saudi national labor forces. Ironically, the constraints on female employment mean that women in the workforce are generally much better qualified than men, with half of working women possessing a college degree, compared to only 16 percent of men" (as cited in AlSaleh, 2012, p.126).

Even though women face various obstacles to reach their utmost potential, more women will join the work force due to globalization. The importance of women employment in Saudi Arabia is increasing. A research conducted by Oxford Strategic Consulting (2012) explains that if Saudi Arabia raises its female work force participation to 40 percent (which is still lower than most G20 economies), it could increase the Gross Domestic Product (GDP) by $\$ 17$ billion, which could add $\$ 58$ billion in revenues to Saudi companies. This would also increase productivity, engagement, and innovation in the country as a whole. 


\section{Research Methodology}

The research involved a primary (original) survey that was sent to interior design companies, who have experience in the Saudi market and could share their knowledge and know-how. A previous study by Al-Ahmadi (2011) concluded that the information of women leaders in the private and public sector is not adequate; hence obtaining the required information was through accessing the women's branch of the Institute of Public Administration. For this research, finding the right way to approach the participants for the study was key.

Interior design Companies were the focus of the study because there is a lack of information about how they operate and hire women employees. There are various studies about entrepreneurship and the challenges that women in Saudi Arabia face, but not specific to the design field. Also, there aren't any studies about the different educational backgrounds Saudi students have. However, based on a national survey of business women, the most common areas reflecting growing access to education for women and especially in higher education are, "art-based, including fashion, jewelry, interior design, and photography" (Danish \& Smith, 2012). Hence, art and design is becoming of interest in Saudi Arabia, particularly women, and can be part of creating jobs for the creative generation. As a result, there is no actual information on how women can get into the design work field and especially in interior design.

Therefore, primary data was collected from seven interior design firms in Riyadh and Jeddah, where some of the most prominent companies are located. Riyadh is the capital of Saudi Arabia and Jeddah is located in the western region and is second largest 
city after Riyadh the capital. The list of companies was compiled directly by the researcher through Internet research and utilizing social media platforms using keywords such as, interior design firms in Saudi, design in Riyadh and, Jeddah interiors. Also, Some design firms were references given to the researcher by friends and colleagues who are in the design field and have the knowledge of other design firms. The method of "snowballing" is used because of the lack of official databases that contain the names and information of the companies needed.

Gathering information to conduct research on women throughout the region is particularly difficult due to cultural constraints (Atkinson,2007: Sohail and Al-Abdali, 2005 cited in Ahmad 2011, p. 130).Finding creative solutions for assisting women in finding design jobs or starting their own design firm was the essence of this research. The participants are professionals managing interior design firms in Saudi Arabia, specifically in the Cities of Riyadh and Jeddah.

This study seeks to learn and understand:

RQ1: How are employees, in particular females, in Saudi Arabia able to obtain appropriate training that provides them with the uncategorized skills, in agreement with the Ninth Development Plan, needed to work in the interior design profession?

RQ2: How is communication between males and females work sections facilitated within a stratified work environment and use of technology? Does the work environment actually suggest stratification and/or privilege? 
RQ3: What technologies and software can best be adapted in a firm to complete interior design projects?

The research started with the trial of identifying the number of established interior design firms in Saudi Arabia. Twenty interior design firms have been identified, between Jeddah and Riyadh. The process started with sending out online surveys in both Arabic and English, giving the participant the choice of choosing the preferred language to answer. A letter of consent was sent along with the link to the online survey if they agree to participate. The surveys were first done in English then translated into Arabic by a professional translator then back translated into English. Therefore, the English version that was sent along with the Arabic version was back translated considering that the target audience is in Saudi and English is their second language.

Choosing these participants may help in understanding the interior design field from a local perspective, working culture, and what facilitates running a productive and successful interior design firm that employs females who dominate the field. Given the exploratory nature of the research, a mixed method approach was used. There were both qualitative and quantitative elements. The qualitative questions, the participant answered in his/her own words open-ended questions. The quantitative questions were utilized to gather information about the demographics. Having the qualitative questions was essential, "Qualitative researchers stress the socially constructed nature of reality, the intimate relationship between the researcher and the researched and the situational constraints that shape reality" (Denzin and Lincoln 2000, cited in Ahmad 2011, p. 130). 
Survey distribution and Data analysis was conducted using the Survey Monkey. The descriptive statistical analysis was conducted for the quantitative questions. The qualitative questions have been examined and coded manually to establish trends and common themes.

\section{Results and Discussion}

\section{Firm Location}

One of the questions that was asked on the survey is the location of the company. Out of the 6 participants who answered the question, 4 participant firms (66.7 \%) were located in a commercial area. The rest of the participant firms were located in residential areas. Furthermore, one of the participants highlighted that the residential area was introducing some commercial activities in the neighborhood. Such as offices and retail spaces. One participant mentioned that their firm's location is considered to be part of a mixed used area with both commercial and residential facilities. This might mean that there is a shift in the demand of the market. Since Residential neighborhoods are changing to accommodate commercial services such as shops and offices where the most these areas had was a small minimart. 


\section{Demographic Questions}

Participants were asked about their position in the firm, then about their gender and age range, and last about their education qualifications. First, the participants were asked about their position in the firm by choosing one of the following options: 1)

designer (engineer), 2) Firm owner, 3) manager of the design department, or 4) firm owner and manager of the design department. The majority of the participants $57.1 \%$ were the firm owners and design managers of design team. The rest of the options were equally matched at $14.3 \%$.

Second, the participants were asked about their gender. The results showed that the majority were female $71.41 \%$ compared to $28.6 \%$ male. This supports the literature that indicates that female university students are drawn to the art and design field.

\begin{tabular}{|l|l|l|}
\hline Demographic Characteristics & $\begin{array}{l}\text { Percentage of } \\
\text { Females }\end{array}$ & $\begin{array}{l}\text { Percentage of } \\
\text { Males }\end{array}$ \\
\hline Designer (engineer) & $14.2 \%$ & $0 \%$ \\
\hline Firm Owner & $0 \%$ & $0 \%$ \\
\hline Manager of Firm & $14.2 \%$ & $0 \%$ \\
\hline Owner and Manager of Firm & $42.8 \%$ & $28.5 \%$ \\
\hline
\end{tabular}

\section{Table 1}

Demographics Of Design Firm Participants

By looking at table 1 we can correlate that interior design firms can be run and managed by females. Perhaps, their education background and their surrounding support helped these women be in these positions.

Third, the participants were asked about their age group. All the participants fell between the 24 - 45 age group. 
The age ranges unveil the possible correlation between the recent graduates in interior design and the young demographic of the participants. The qualifications in question included the following: 1) university name, 2) level of degree obtained, 3) specialization and 4) country the degree was obtained.

The majority of the participants $71.4 \%$, obtained their education internationally,

giving the edge of international exposure and the rest $28.6 \%$ obtained it locally in Saudi Arabia. The majority of the participants $85.7 \%$ have degrees related to interior design.

Various questions arise when looking at these results. First, whether if education being obtained internationally or locally made a difference when the participants were looking for a job? Second, does "prestige" play a role in choosing an international institution to obtain education or is it that local universities do not match the education standards of international universities? Third, do these participants look for designers with qualifications similar to their own?

\section{Number Of Designers Working For The Firm}

The following table (2) illustrates the number of female and male employees working at the design firm and the number of outsourced employees. The results indicate that it is a standard operating procedure to outsource employees. In general, the participating firms are fairly equal in number of employees, accept one that might be a more prominent firm that provides different types of services.

The fact that these design firms have outsourced employees highlights an important issue. It is a possibility for females who have the qualifications needed by a 
design firm to be hired remotely. This relates highly to the concept of flexible hours that the majority of the female Saudi population prefers when looking for a job. Having flexible working hours gives women the chance of balancing what society and culture expects from them, such as being housewives, and fulfilling their desire of becoming successful in the work force. Succeeding in both the household and work obligations would give women grate joy and pride.

As the study by Oxford strategic consulting (2012) states, the majority of females who wish to work part time across all ages, regions of the country and with different types of degrees represent $56 \%$ of the population, but nearly all employers are only considering full time employment models, which is $86 \%$. The outsourcing option could be a solution to increase the employment rates for women in the design sector.

\begin{tabular}{|l|l|l|l|l|}
\hline $\begin{array}{l}\text { Participating } \\
\text { Design Firm }\end{array}$ & $\begin{array}{l}\text { Number of } \\
\text { female }\end{array}$ & $\begin{array}{l}\text { Number of } \\
\text { male }\end{array}$ & $\begin{array}{l}\text { Total of male } \\
\text { and female }\end{array}$ & $\begin{array}{l}\text { Number of } \\
\text { outsourced } \\
\text { employees }\end{array}$ \\
\hline A & 4 & 2 & 6 & 2 \\
\hline B & 2 & 4 & 6 & 0 \\
\hline C & 15 & $\sim 300$ & 315 & 5 \\
\hline D & 3 & 5 & 8 & 5 \\
\hline E & 1 & 2 & 3 & 2 \\
\hline F & 2 & 3 & 5 & 6 \\
\hline G & 3 & 1 & 4 & 3 \\
\hline Total & 30 & 317 & 347 & 23 \\
\hline
\end{tabular}

Table 2

Number Of Designers Working For The Design Firm 


\section{Qualifications For The Hiring Process}

The design firms were asked to voice their opinion on the most important factor in the hiring process. The options they were given were: 1) Degree obtained, 2) Experience, or 3) a portfolio. Both experience and portfolio had the same $42.9 \%$, which is higher than $14.3 \%$ for the degree obtained. Because of the small sample size we can't have a concrete answer on which is the most sought after qualification when being considered for an interior design position.

In general, experience and portfolio seem to have an effect on who is hired. This supports what Levins (2006) states, a key factor in the hiring process is a portfolio because a lot of people can be talented in design and have the adequate experience but not have a degree in design. As one of the participants said

"Portfolio reflects the degree of creativity, professionalism, philosophy, and mentality of the candidate in addition to the interview"

\section{Transportation}

The participants were asked about transportation in Saudi Arabia in two questions. First, how do the female employees obtain transportation to and from work? And second, what transportation options would be most beneficial to female employees and hence for design firms? These 2 questions will be analyzed side by side intentionally.

The most common answers for how the employees commute to work are:

- The company provides a transportation allowance 
- The employees are responsible of their own transportation, such as, a taxi, family member or a personal driver

- The company provides employee drivers

The most common answers for the most beneficial transportation solutions for female employees are:

- Support of women driving in Saudi Arabia

- The option of having new and secure options for public transportation such as metro's or taxi services

- Company drivers

It was discovered that these two questions and information could be combined. The findings support each other and inform one another. One of the issues that many women in Saudi Arabia face is the lack convenient transportation options. Looking at the results one can only say that there are some efforts by the companies to help female employees commute to work. This brings to light the other companies, who can't afford providing these services, what alternatives can they utilize. All the mentioned solutions are options that can be implemented to help solve this dilemma. One of the participants mentioned that in Saudi Arabia, a service called Uber, which is a new way of using a public transportation has been introduced to various cities around Saudi Arabia. As (Uber 2014) website nicely states "Uber is evolving the way the world moves. By seamlessly connecting riders to drivers through our apps, we make cities more accessible, opening up more possibilities for riders and more business for drivers. From our founding in 2009 to our launches in over 200 cities today, Uber's rapidly expanding global presence 
continues to bring people and their cities closer." The idea of the Saudi culture using Uber means that they are on the track for finding transportation solutions. They are on the road of utilizing modern and high-tech as a means to solving problems.

\section{Segregation}

There were several questions on the survey that addressed issues that relate to segregation. The first question is: are their separate main entrances for both male and female employees? The majority of the participants reported that they do not have separate entrances. This generally indicates that the company is located within a building and the main entry of the office is for all employees that lead to various offices within the firm.

This leads to the Second question about whether there were separate working sections within the firm for male and female employees to work? The results were almost equal at $57.1 \%$ that said yes they have separate working sections. The rest of the participants $42.9 \%$ said no, they don't have separate working sections.

All participants who replied by yes or no were asked about the various ways their employees collaborate with one another within their working areas. The participants who replied with yes mentioned that meeting rooms and telecommunication (email, phone) are the ways their employees collaborated to complete their projects. And, the participants who replied with no mentioned that their employees work in open plan spaces where the head of the design team is always available to overlook the employees. As one of the participants says 
"It is an open environment and one of the partners is always in charge. And, that is why we chose our team members carefully"

It has been mentioned by Sidiya \& Al-Jaseem (2010) that there are many companies that don't think of hiring women because modifying the workspace to accommodate a women's section is expensive to implement and design. Also, creating a separate area in an existing interior to accommodate this demand is costly (as cited in Vaid, 2011, p.446). Even though the general perception is that a company cannot be run unless there are separate sections our results indicate differently. Perhaps these companies could be pioneers of eliminating any obstacles that hinder women from working for a design firm.

\section{Jobs, Technology and Skills}

The following results correspond to the various technologies that employees use to complete the projects, and working in teams. Also, what makes them equip to be designers at the firm and what the firm provides their designers to stay up to date with technology and design?

First, the participants were asked about what software do the designers use to complete their projects? The 7 participants shared the following answers:

AutoCad, 3dMax, SketchUp, Revit and Adobe Suits including Photoshop, 
Illustrator, and InDesign

Second, the participants were asked what their employees' qualifications were to become designers.

The majority of the employees $85.7 \%$ have a 4 -year bachelors degree in interior design. Therefore, a 4-year B.S was a big factor in the hiring process. But this is not to be generalized, because as the previous section mentions, that there is a $42.9 \%$ for each of the portfolio and work experience being factors for the hiring process. Hence, having a degree in another field of education is not an indicator of failure in being part of the design work force, on the contrary, ones portfolio and experience in the design field is enough as an indicator of capabilities and skills. Perhaps, since the owners that are the majority of the participants had a 4-year bachelor degree, would in return look for employees that have similar qualifications, or would invest in the training of their employees.

Third, the participants were asked about how the designers developed their skills?

The main answers were around

- Improving on their education

- Designers developing their skills through their work experience, through client meetings and being involved in the project design process

- Online training and workshops 
Most of the respondents stated that training for designers started with their 4-year design degree then moved to company training and hands on work experience.

\section{Conclusion}

The findings of this research indicate a broad conclusion that women are dominating the art and design field and specially interior design in Saudi Arabia, which in return supports the research in finding solutions for women to get into the design field. Women in Saudi Arabia play a big role in boosting the economy looking at this niche in this up and coming market will create opportunities for the creative individuals who want to be part of the working class. The result of the Ninth Development Plan is translated into support for women empowerment through education and creating job opportunities. This research shows that there is a demand for jobs in the design sector. Technology plays a big role in a society that is very much affected by culture. Technology is a means in bringing people together under one roof for convenience of the user. The results indicate that the use of high tech applications is one way of solving the dilemma that Saudi women face.

As the findings suggest, the following actions should improve the situation for creative women who want to be in the interior design field and be part of the work force. First, Designers should know that applying for an interior design job requires representing one self through a portfolio that showcases all projects and past experiences. Second, Having an education regardless if obtained locally in Saudi Arabia or abroad, should comply with international standards. Third, Having segregated spaces within a 
design firm should not be an obstacle for hiring women; finding creative solutions for both males and females to work under one roof is the answer. Fourth, Flexible working hours through technology can be achieved considering that it is the demand of the majority of females in Saudi to work part time. Hence, firms should consider various working hours when looking to hire designers. Fifth, Transportation problems can be solved when firms create the means of commuting. Sixth, learning various design applications through the firms training or independently is necessary to be considered for a job. Lastly, creating women training centers will broaden women's skills and promote talent collaborations.

In conclusion, the results of the study indicate the there is a demand for job opportunities in the interior design field. Creating jobs for women in Saudi is not just for the country's economic growth but also for the women's self -dependency. Educated women regardless whether if their education was obtained locally of internationally should be confidant to apply and be part of the design scene. Experience and skill is vital because it is what firms look for when hiring designers. 


\section{References}

Aguirre, D., Hoteit, L., Rupp, C., \& Sabbagh, K. (2012). Empowering the third billion: Women and the world of work in 2012. Booz.

Ahmad, S. Z. (2011). Evidence of the characteristics of women entrepreneurs in the kingdom of saudi arabia: An empirical investigation. International Journal of Gender and Entrepreneurship, 3(2), 123-143. doi:10.1108/1756626111114020.

Al-Ahmadi, H. (2011). Challenges facing women leaders in saudi arabia. Human Resource Development International, 14(2), 149-166. doi:10.1080/13678868.2011.558311

Aldraehim, M. S. (2013). Cultural impact on e-service use in Saudi Arabia. PhD thesis.

Alsaleh, S. A. (2012). Gender inequality in Saudi Arabia: Myth and reality. International Proceedings of Economics Development \& Research, 39.

Brief Report on the Ninth Development Plan. (2010).

Danish, A. Y., \& Smith, H. L. (2012). Female entrepreneurship in saudi arabia: Opportunities and challenges. International Journal of Gender and Entrepreneurship, 4(3), 216-235. doi:10.1108/17566261211264136

Fact Book: Saudi Arabia. (n.d.). Fact book: Saudi arabia. [Web page]. Retrieved from https://www.cia.gov/library/ publications/the-world-factbook/geos/sa.html .

Le Renard, A. (2008). Only for women:" Women, the state, and reform in Saudi Arabia. The Middle East Journal, 62(4), 610-629.

Levins, K. E. (2006). The impact of creativity on the evaluation of entry-level interior design portfolios: Examining the relationships among creative novelty, resolution, and style. Thesis.

Maximising the Employment of Saudi Females. (2012). Maximising the employment of saudi females. Oxford strategic consulting. Retrieved from www.employingwomen.com

MENA_Gender_Compendium-2009-1.pdf. (n.d.). 
Smith, S. R., \& Hamon R. H. (2012). Exploring Family Theories. New york, Newyork: Oxford University Press, Inc.

Vaid. (2011). Saudi women and entrepreneurship: Opportunities in architecture and interior design: Bright future for new graduates. Middle East Studies Online Journal, 3(6). Retrieved from Google Scholar.

White, J.W., \& Klein, D.M. (2008). Family theories. Los Angeles: Sage Publications. 


\section{CHAPTER II \\ EXTENDED LITERATURE REVIEW}

\section{Introduction}

There are various realities that shape the Kingdom of Saudi Arabia and differentiate it from other countries in the world, and even surprisingly from the rest of the Middle Eastern and gulf countries. Saudi Arabia is one of the most visited countries in the Middle East by Muslims from all over the world because it is the home of the two Holy mosques in Makkah and Madinah. The country's constitution is the Holy Qur'an, which is ruled on the basis of the Islamic law (Shari'a). As Aldraehim (2013) explains, "Islam is the first element of Saudi Arabia's culture and sets the moral principles and behaviors in its society through the Koran (the holy book) and the Sunna (the sayings and practices of the prophet Mohammed peace be upon him).'This plays a big role on the culture of the country and the people's way of life.

The political structure of Saudi Arabia is shaped around the religion as the constitution of the country. There are various limitations that the people of Saudi face especially women because of the culture and the way of life in the kingdom such as segregation and the ban of women driving. Law prohibits women and men engaging with 
one another in public and private spaces, which creates the concept of segregation. Segregation simply means that women and men have separate working, meeting, and socializing areas in public and private spaces. Some of the areas that follow the segregation rule are restaurants, banks, offices and malls, where there is a separate main entrance for each males or females. A typical entry door has a signage that indicates which entrance is either for men, women or families. The strict segregation between women and men's places has been established legally and maintained with modernization in mind since the 1960's (LeRenard, 2008). Another obstacle that women face is the law that prohibits women from driving. In fact Saudi Arabia is the only country where women are not allowed to drive, and this fact merely exists because of cultural reasons.

Many outsiders who look at Saudi Arabia have the misconceived notion that these issues that women face make it difficult for women to have an easy and convenient life, but is this is really the case? Both women's educational level and daily activities have completely changed over the past 50 years and within a "female sphere," where entry for men is forbidden (LeRenard, 2008). Even though gender segregation might seem to be depriving women and men of many outlets for their activities, it opens up others doors at the same time for women to create spaces and areas that they can meet and socialize. The spaces that they create become the starting point of every action, and successively expanding women's activities, which involves the expansion of segregated spaces that leads to strengthening women as a category in society (LeRenard, 2008).

Women have always been an integral part of society, the household sector and the economy. Women in the past worked to earn money in the fields and through crafts. As Almana mentions, bedouin women also participated in family work activities such as 
camel and sheep breeding (as cited in LeRenard, 2008, p.613). Also, Almana says, these same women who once needed to work, stopped simply because of the economic boom in the Kingdom and relied on their husbands who had enough income to provide for their families. In addition exported goods became cheaper than local goods therefore women no longer had to work in the fields to produce goods locally (as cited in LeRenard, 2008, p.613). Women stayed in the comfort of their homes where all their necessities were met.

As Inglehart and Norris (2004) mention, Western activists argued that women in Saudi Arabia, whether at home or in the work place, are overpowered persons and have no say in any decision making. They think that moving toward achieving equality, in the home, in the workplace, and in positions of education, health and political power, remains one of the most important challenges facing the Saudi government in the twentyfirst century (as cited in Alsaleh, 2012, p. 123).

The purpose of this study is to document the current business operations of interior design firms in Saudi Arabia. The intent is to explore how the current support for the education of Saudi females can be translated into employment and training within the profession of interior design.

\section{The Ninth Development Plan And The Feminist Theory}

Now in the $21^{\text {st }}$ century, with all the new advancements in Saudi Arabia there is access to the outside world through technology. Women want to stand out and be part of society and especially part of the working class. Finding the balance between the culture and way of life in modern Saudi is the challenge that some women face to become 
successful and be part of society to the fullest. The government plays a big role in finding a solution to women's obstacles. Women are a big part of the four-year developmental plans of Saudi Arabia, and most recently in the Ninth Development Plan which spans from 2010-2014 issued by the Ministry of Economy and Planning. As defined by the ministry of Economy and planning (2010, p.7), “The Ninth Development Plan is a continuation of the developmental approach adopted by the Kingdom throughout the past four decades. This approach combines the directive planning of government activity and indicative planning of private activity within a framework of developmental paths and the future vision defined by the long-term strategic planning."

When talking about social and cultural aspects, the association of these to the community as a whole and the wellbeing of a countries people is a must. A society cannot improve as a whole without looking deeper into roots. In Saudi Arabia, women have been categorized as a marginalized group within the society because of reasons such the state rules and the segregation between men and women that has repercussions on attitudes and the design of spaces (LeRenard, 2008). Feminist theorists who are essentially focused on changing the social experiences and understandings of women give women as a marginalized category great attention. Working in parallel with some of the goals of the Ninth Development Plans, the feminist theory could illuminate status differences between genders so women can be empowered (Smith \& Hamon, 2012).

Some of the major themes that are integrated in the Ninth Developmental Plan address the economy of the Kingdom of Saudi Arabia by focusing on women and the family as a whole in the coming years. The following are the main headlines that mentions women as a minority group that should be given great attention in the society 
(Ministry of Economy and Planning, 2010):

- " Enhancing and intensifying efforts to improve citizens standard of living and promote their quality of life"

- "Paying attention to the social dimension of the development through enhancing private participation in the process of development, social care, support of needy categories and groups with special needs, and giving special attention to youth, women and children"

- "To support efforts to increase participation of the national workforce (males and females) in the labor market"

- "To promote the effective participation of Saudi women in the Kingdom's development"

The above tenets fit readily into the basic assumption of feminist theory. Particularly with "emphasis placed on social change" (Smith \& Hamon, 2012, p.296) and the need for application of the theory to be emancipators (white \& klein, 2008).

However, There are still various cultural issues that stand in the way of women reaching their goals. Feminist theorists believe that biased gender roles are a reason behind these obstacles. These theorists support the idea that society plays a big part in assigning roles to each gender. As a society that is significantly affected by its culture, Saudi citizens have labels automatically placed on them based on their sex, whether for occupational, economic, or status reasons.

The construction of assigned gender roles has been part of various societies not only in the Kingdom but also around the world (Smith \& Hamon, 2012). 
White \& Klein (2008) state, "Gender structures all societies.” Gender is used as a basic class distinction in all societies. It is a cultural symbol that helps construct social class. As Aldraehim (2013, p, 14) states, “a nation's culture in general involves the observation of rules, customs, responsibilities, and morals, which are influenced by language, gender dynamics, race, beliefs, geography, work and other factors. All of these aspects influence interpersonal needs." Interpersonal needs in this situation are the Saudi Arabian women's needs as they are the category in focus.

Research done by Aguirre, Hoteit, Rupp and Sabbagh (2012) has named all women in the world as the "Third Billion." They have statistical evidence that women are still not fully recognized in many countries and especially in the Middle East and the Gulf countries. The Third Billion have not received sufficient attention from governments, business leaders, or other key decision makers in many countries. The kingdom of Saudi Arabia is experiencing tremendous growth as the population has tripled over the last 30 years with a median age of 25.3 years (CIA, 2011). Within this population are women, who despite what people believe, have an integral role to the overall growth of the Kingdom. Through education and job opportunities, women can make a great difference in the overall economy of the country. However, work needs to be done to ensure women's full participation in the Saudi family, work place, and society.

In Saudi Arabia, education has been identified not only as a source for the empowerment of women but also as being vital to "the economic survival of the country in years to come" (Danish \& Smith, 2012). The large pool of educated women, whose talent remains largely untapped, will be crucial to this evolution. As Kaaki (2010) says, "Investment in girls education may well be the highest return investment available in the 
developing world" (as cited in Vaid, 2011,p.450). Education has been a segregated sector in Saudi Arabia since the 1960's and remains till now (LeRenard, 2008). This played a role in bringing women from different background to socialize under one roof and meet one another.

Saudi Arabia is ranked $123^{\text {rd }}$ among the countries who are "at the starting gate" of empowering women in the economy by providing more opportunities and realizing their value to the overall society (Aguirre, et. al. 2012). Even though women have cultural and religious barriers that prevent them sometimes from enrolling in higher education, the number of women receiving a higher education, whether in their home country or abroad, has increased over the years because of the investment in the scholarship programs. Educated women are valuable assets to society. They represent 57 percent of university graduates in Saudi Arabia, but unfortunately are still under represented in the workforce, and stratified in terms of feminist theory (Smith \& Hamon, 2012). The unemployment rate for women is 28 percent, compared to 7 percent for men (Aguirre, et. al. 2012). Mena Gender Compendium (2009) explains, “Women's' function in the wider society is limited and Saudi Arabia has one of the lowest participation of women in the workplace, particularly graduates.”

Al-Mohamed (2008) states that as the educational opportunities for women rapidly progresses an increase in the number of women in the work force should be the next step. The author also says, "Currently, roughly 300,000 Saudi women work, comprising five percent of the Saudi national labor forces. Ironically, the constraints on female employment mean that women in the workforce are generally much better qualified than men, with half of working women possessing a college degree, compared 
to only 16 percent of men" (as cited in AlSaleh, 2012, p.126).

Even though women face various obstacles to reach their utmost potential, more women will join the work force due to globalization. The importance of women employment in Saudi Arabia is increasing. A research conducted by Oxford Strategic Consulting (2012) explains that if Saudi Arabia raises its female work force participation to 40 percent (which is still lower than most G20 economies), it could increase the Gross Domestic Product (GDP) by $\$ 17$ billion, which could add $\$ 58$ billion in revenues to Saudi companies. This would also increase productivity, engagement, and innovation in the country as a whole.

\section{Challenges That Women Face To Be Part Of The Workforce In Saudi}

\section{Arabia}

\section{Transportation Obstacles}

"There are women out there desperate to find jobs," says Samar Fatany, a leading Saudi feminist author (as cited in Sullivan, 2012). Helping this category find job opportunities would be the next step. It is important to address the situation of the unemployment of women by finding a solution that will give them a chance to work not only to achieve financial stability but also to support positive feelings of self-worth. Success in obtaining both a job and being independent, will prove that women in the Middle East can do anything when given the chance. Knowing the obstacles women face 
on a daily basis and the ways they deal with it is important in solving the unemployment impasse. One of the issues that have been mentioned briefly before is the ban on driving, the absence of public transportation and restrictions on international travel create obstacles for women. There is a lack of adequate public transportation for women. Women have to rely on personal drivers, when a male figure in the family isn't available or can't accommodate the needs of his female family members. Also, hiring a driver could be a financial burden for some families. An alternative for women would be the use of taxis. However, it may be awkward and culturally unaccepted by locals. Currently women cannot use public transportation such as buses. The bus system that is currently available is inappropriate. It does not accommodate the segregation law of having both male and female. Also, the buses that are now used are outdated and small to accommodate many passengers. Women cannot use buses and be in close proximity with men. It is a cultural and religious limitation that will make women and men alike uncomfortable. One new transportation option is the metro system. The government is currently building metro systems in Jeddah and Riyadh to help solve the issue of transportation in the country. Hopefully this will solve part of the transportation dilemma. 


\section{Employment Options For Saudi Females}

The second issue that women face is finding the right type of employment option such as full-time, part-time or even from a distance as working remotely from home. It has been shown that the majority of females wish to work part time across all ages, regions of the country and with different types of education degrees. These women represent 56 percent of the population but nearly all employers are only considering full time employment models, which is 86 percent (Oxford strategic consulting, 2012). Having flexible working hours gives women the chance of balancing what society and culture expects from them, such as being housewives, and fulfilling their desire of becoming successful in the work force. Succeeding in both the household and work obligations would give women grate joy and pride.

There are various ways that companies can help employ women, not only for the women's benefit but also for their companies benefit as well. Oxford strategic consulting (2012) recommends that a company employ females on flexible terms such as working from local centers, work from home, and providing call center and IT support services. This solution could address a current potential market of 160,000 client companies, capable of providing outsource work for the equivalent of $4.5 \mathrm{~m}$ full time females. Private companies can leverage their power as investors by promoting gender equity in the workplace providing financing for women-owned businesses; and developing jobs, products, and services that benefit women. This will go hand in hand with the current 
countries Ninth Development Plan that encourages women empowerment.

\section{Training And Support}

In a place like Saudi Arabia, Creativity and innovation plays a big role in many ways. Obstacles create opportunities for women to be creative in creating a place for them to work, and generate business ideas. Some women create home-based businesses because it provides them the independence and flexibility they prefer. However, there are a large number of women who are financially unable to start their own business and work from home. These women would like to be part of a large network of women who can support them and make them part of the work force.

Being part of the work force is not an easy task. It requires training and experience, which without women have to face yet another hurdle. There is a lack of adequate training for women in various fields of education, even though there are efforts made to provide it. In Saudi Arabia, all of the chambers of commerce have training centers. As Bab Rizq Jameel (2010) mentions, training centers in Saudi are funded by $12 \%$ fees, collected from every company by the Saudi Arabian General Investment Authority (SAGIA). Bab Rizq Jameel (BRJ) with the support of private and public sectors creates jobs, training programs, and provides interest free loans for women especially who work from their homes. The executive director of BRJ Abdulrahman Abdulaziz Al Fihaid said recently, women were offered a computer and a training course entitled, "How to start your small project" (as cited in Vaid, 2011, p. 452). But, what 
about women who want to get into the design field, are there training courses for them?

WIN News (2003) mentions that, it is clear that women in Saudi Arabia have serious problems to deal with, but many are irritated by what the outside world thinks of as problem. Problems such as the segregation or the ban of driving are not the main issues women face, women in Saudi Arabia believe the most important issue they are facing is finding a job. "They are not bothered by what others perceive them to be, but they deal with the real worries, issues and ambitions" (cited in Alsweel, n.d, p. 12). It is true that Saudi women may seem silent and obedient but the reality is, they are very aware of their situation and are working hard on changing it (Alsweel, n.d).

There are many roads that could lead into helping women achieve their goals. Employers, investors, and consumers in private-sector companies have a number of roles to play in empowering women. By hiring women in developing markets, they can facilitate women's independence and increase their standing in society. Around 385,000 degreed level females are available in the market, but not currently utilized, while Saudi research suggests the private sector has the theoretical capacity to employ at least $7 \mathrm{~m}$ females (Oxford strategic consulting, 2012). One great example of an organization that is already helping empower women is the Khadija Bint Khuwailed Centre. It is a professional organization for women belonging to the local Chamber of Commerce in Jeddah in Saudi Arabia. Established November 2004 (Danish \& Smith, 2012) the center's vision is to eliminate all obstacles that women face and support their participation in the national economic development (Alturki \& Braswell, 2010). 


\section{Work Location}

It maybe true that the Saudi labor laws may limit the places where women work, however at the same time these same limitations open up a legitimate workspace for women. For example, because women are not allowed to work in banks, and because Islamic principles justify women's use of banks, new banks for women run by women were established, thus providing more job opportunities. Similarly, many labor laws that protect women are very progressive in their benefits. For example, women workers are entitled to a ten-week fully paid maternity leave, and once they return they have daily time off for nursing. Women also receive medical coverage and cannot be fired during pregnancy leave (Doumato, 1992, cited in alsweel, n.d, p.9). This creates a balance between what the society demands and what women want to achieve. Recently the government liberalized the labor laws slightly to allow women work in supermarkets and retail shops especially those that sell women clothing and intimates. This is a great step toward helping women particularly those without degrees who need to support their families or themselves financially.

A physical place for women to work is needed for them to be part of the work force. In Saudi Arabia in particular, as mentioned before, there is the concept of segregation. There are many companies that don't think of hiring women because modifying the workspace to accommodate a women's section is expensive to implement and design. Also, creating a separate area in an existing interior to accommodate this demand is costly (Sidiya \& Al-Jaseem, 2010, as cited in Vaid, 2011, p.446). Even women owned businesses have to abide with the designated women only section with a separate 
entry and exit doors and male supervisor in the men's section (Parker, 2007 as cited in Mckenna, 2009, p.7). Hence, not having separate working spaces is a hurdle in hiring women in some cases.

\section{Interior Design}

\section{Interior Design's Education And Profession In Saudi Arabia}

It is expected that the number of women joining the work field, whether for economical or other reasons will increase. They will join the work field keeping in mind that they must do so within the segregated structure of the Saudi society. Being able to accommodate the needs of women while they are in a separate working section through the use of technology creates many possibilities. "Saudi women are already keen users of the Internet in Saudi Arabia, and this enhances their opportunities to telecommute from home and to engage in e-business" (Tarbush, 2000 as cited in Alsweel, n.d, p. 9). As they face many obstacles to reach their goals in life and especially in the working force, a Saudi women's freedom to choose her profession is limited more by social than legal norms (Ahmad, 2011).

As Alshaibi (2011) states, despite the fact that women's participation in the mechanical engineering, interior design or law fields wasn't an option because the higher education in these fields was not widely acceptable, nowadays these fields are available to women and signal job opportunities in these markets (Alshaibi, 2011). In Saudi Arabia, based on a national survey of business women, the most common areas reflecting 
growing access to education for women and especially in higher education are, "artbased, including fashion, jewelry, interior design, and photography” (Danish \& Smith, 2012). Designers are armed with a unique way of thinking: inherently generative, proactive, and focused on creating new possibilities for the future which promises hope for inspiring the design field (Danko, 2010).

Every culture believes that there is a certain occupation that stands out and gives a person a certain social class within its society. And of course, the inevitable stereotype of what is expected as a suitable occupation in regards to gender. As Alajmi (2001) mentions, stereotypes are strongly rooted in the Saudi Arabian culture, manifested themselves in various aspects including, gender segregation, restriction to women mobility, and gendered occupational structures (as cited in Elamin \& Omair, 2010, p.760). Occupational stereotypes are everywhere in the world. Ahmad \& Ali (2013) say that most Canadian parents (94\%) want their kids to be doctors and that most likely all Asian parents desire the same for their children. The authors also mention an interesting issue, in Saudi Arabia being an engineer is similar to being a doctor. People grant engineers respect and they are recognized as holding a respectful position. Being an Interior Design graduate holder is similar to those graduates in the field of engineering, Where Interior Design graduates can enjoy engineer's privileges in KSA (Ahmad \& Ali 2013).

The fact that many students are getting into the art domain raises the question how can this field of study be more accessible to women? Vaid (2013) states that there is a high number of Saudi graduates who hold design degrees such as 
engineering, architecture, and interior design due to the King Abdullah scholarship programs that the country provides for both men and women. Hence, the need to create more jobs in the design field should be the next step. The country invests in thousands of students who travel the world to obtain their higher degrees through the King Abdullah scholarship program.

The program gives the students whether men or women a chance to excel in their education. These students when back in the country are great assets to the local economy, and a great honor playing their part in the country's growing population of educated individuals.

The interior design profession is not always fully understood. Many people use the terms "interior design" and "interior decorating" interchangeably, but these professions differ in critical ways. Tarver (2013) explains the difference, interior design is the art and science of understanding people's behavior to create functional spaces within a building. Decoration is the furnishing or adorning of a space with fashionable or beautiful things. In short, interior designers may decorate, but decorators do not design.

Interior design is not only taught internationally but locally too. An interesting fact that is mentioned by Ahmad \& Ali (2013) is that, presently interior design programs in Saudi Arabia are offered only to female students. The interior design programs are designed to suit female working environments where segregation of the sexes is applied in Saudi Arabia. Also, female interior designers are not expected to 
be working in the fields of construction, because it is considered to be a man's field (Ahmad \& Ali, 2013). Even though this is a broad statement that many women would take offense from, women in the creative industry should look at it as an opportunity. It creates a strong argument to help more designers and artistic talents to join the design field. What also supports the claim that there is a vast number of female design graduates is that there are the local universities that provide art and design programs for females only. Some of the universities are: Prince Sultan University (PSU) in Riyadh, Prince Mohamad bin Fahd University (PMU) in Dammam, King Abdulaziz University (KAU) in Jeddah, Dar Al-Hekma College (DAC) in Jeddah, University of Dammam (UD), Yanbu University College (YUC) in Yanbu. Hence, local and international design educated Saudi graduates should be considered when looking for individuals who would bolster the Saudi design scene.

\section{Technology In The Interior Design Field}

Saudi Arabia is considered one of the developing countries that had made vigorous efforts towards transforming itself into an information society by investing in information technology and integrating it into various sectors including the education sector (Alhareth, McBride, Prior, Leigh, Flick, 2013). Technology is usually produced in developed countries, and consequently is "culturally- biased" in favor of its own social and cultural values (Straub et al., 2001;p.3 as cited in Aldraehim, 2013, p. 15). This in return creates cultural and social barriers in their use 
in the developing countries.

According to (Aldhafeeri, Almulla and Alraqas, 2006), one of the most used learning tools in the Middle East is E-learning. Introducing E-learning to a sensitive culture such as Saudi should be done carefully. It has been used in the education sector to expand female opportunities, why not have it transferred to the work sector to help increase women employment rates. Saudi Arabia has invested billions in being a technology-oriented country and providing world-class education. This means as Alhareth (2013) mentions, cultural barriers are sometimes the obstacle and not the financial or technical reasons.

Technology plays a big role in the Saudi Society. It facilitates an easier and more productive facet for women who want to be part of the working and educated class. Women now can research, learn and even work at their convenient time and location. Technology solves the issue of face-to-face interaction, it enables working in teams from a distance, whether it was from home or a separate women's section in a company. In particular companies who have both women's and men's sections would greatly benefit from it. This also solves problems such as saving money, time and worrying about commuting issues. There are various technologies that can be adapted from the education sector to the work sector to support women in the work force, such as software with high quality teleconferencing (e.g., Skype or WebEx) or computer applications. These applications enable seeing the boss and teammates conveniently from home or even from the women's section in the same company with live interaction (Alrashidi, 2013). 
Technology is everywhere, and design firms use it in different ways to stay up to date with the market, keep connected with clients, and in hiring designers. A key factor in the hiring process is a "portfolio" because a lot of people can be talented in design and have the adequate experience but not have a degree in design (Levins ,2006). An example of a portfolio would be a selection of design projects that are compiled by the designer to promote her/his work that was produced over a given period of time. Designers used to collect their work that is all hand-made and compile it in a portfolio that is literally presented physically in book like format on spot. This process was demanding and time consuming. Nowadays, portfolios can be showcased conveniently from a distance, through online portals and websites. There are various websites that can be used to upload portfolios easily such as www.coroflot.com, www.behance.net and www.wix.com. This way companies have the option of hiring talents based on their experience and their individual talents. Technology in this case created flexibility that is key and in line with making it easy for women to apply and work from any location they prefer.

According to ASID (American Society of Interior Designers, 2012) interior design firms are in the business of getting work and getting the work out. They want to know how designers are going to help them do business fast and meet the demand. Living in a fast paced world with new inventions and technologies, companies expect a certain level of proficiency from their designers in computer-aided applications related to the design field. To be successful in the design field one has to be proficient in the use of computer aided design software and especially in AutoCAD (Kirkpatrick, Kirkpatrick, and Freed , 2007). Companies are looking for skilled and talented individuals who can 
add value in a highly technological industry.

Countless companies and higher education institutions have switched to computer aided design software. According to University World News (2008), the major conversion of the Kingdom's traditional education is expected to become E-learning based throughout most universities in Saudi Arabia, as the Saudi Ministry of Education has planned (as cited in Alrashidi, 2013, p. 15). Computer aided design and the technological advancements in the education field and work force help in saving time and being more productive. Using new design applications that are immersed with advanced technology features is used more often nowadays. Old school styles of hand drawing techniques are rarely used because the new applications are more accurate and less time consuming. Companies working with various partners all over the globe take advantage of these applications. Creative applications help team members collaborate instantaneously, giving them more meeting and on the go brain storming sessions. Firms are increasingly engaging in an integrated practice where projects are designed, developed and executed by interactive teams (Cramer, 2006). These teams openly share information and ideas within streamlined delivery protocols fueled by a single technology platform (Hildebrandt, 2010 cited in Tarver, 2013, p. 21). What designers need to function well in the work place is summed up very nicely in the following quote by Sasaki (2004) "It's no longer enough to leave school with drawing and drafting skills, architectural and design knowledge, business and interpersonal skills - you need the expertise to function in a high-tech workplace while incorporating humanistic sensibilities."

Education and Work experience will reach its best potential through the use of the 
high-end technology. The number of students is growing as in turn the number of graduates who would be looking for jobs that are flexible and compatible with the way of life in Saudi Arabia. Empowerment of women through education and work experience aids women in achieving their goals, not only financially but also personally, measured by their satisfaction, happiness and growth. As Omair (2008) mentions, work and education empowers women's self-confidence, expands their social activities and communications, and improves their skills and managerial capabilities, particularly if they have the important support of their families and husbands.

\section{Conclusion}

It is clear that women in Saudi Arabia have to be very creative and resourceful to work in the design field. A principal tenant of feminist theory acknowledges that, " social and historical contexts are important" (Smith \& Hamon, 2012, p.296). Saudi women always have to consider their cultural limitations being in a male dominated society, family responsibilities, transportation difficulties, and the segregation situation. These barriers only make them stronger and keener to create a space for themselves in the community to stand out and make a difference.

As mentioned, Saudi Arabian women face various obstacles to be part of the work force. Using technology for bridging the gap is one way of solving the problem. The various technologies that businesses can adapt are countless. It would help in excelling in the market regardless of business type in an outstanding way. Looking deeper into the 
various backgrounds of women's education, findings show that the arts domain is a dominant specialization in Saudi Arabia. One can only imagine the possibilities if all women under the design and art umbrella would collaborate and work for a design firm that fosters creativity. With the help of designers, Saudi Arabia will look deep within itself as well as abroad to bring about cohesiveness between traditional and modern design implementations (Alshaibi, 2011). 


\section{References}

Aguirre, D., Hoteit, L., Rupp, C., \& Sabbagh, K. (2012). Empowering the third billion: Women and the world of work in 2012. Booz.

Ahmad, A., \& M.Ali, A. A. (2013). The first interior design engineering program in saudi arabia: Relevancy to introduce the program at yanbu university college. Procedia - Social and Behavioral Sciences, 102, 335-339. doi:10.1016/j.sbspro.2013.10.74

Ahmad, S. Z. (2011). Evidence of the characteristics of women entrepreneurs in the kingdom of saudi arabia: An empirical investigation. International Journal of Gender and Entrepreneurship, 3(2), 123-143. doi:10.1108/1756626111114020.

Al Alhareth, Y., McBride, N., Prior, M., Leigh, M., \& Flick, C. (2013). Saudi women and e-learning. In The Future of Education: the Italian publisher.

Aldhafeeri, F., Almulla, M., \& Alraqas, B. (2006). Teachers' expectations of the impact of e- learning on Kuwait's public education system. Social Behavior and Personality, 34(6), 711-728.

Aldraehim, M. S. (2013). Cultural impact on e-service use in Saudi Arabia. $\mathrm{PhD}$ dissertation.

Alrashidi, A. (2013). An exploration of e-learning benefits for Saudi Arabia: Toward policy reform. Thesis.

Alsaleh, S. A. (2012). Gender inequality in Saudi Arabia: Myth and reality. International Proceedings of Economics Development \& Research, 39.

Alshaibi, A. (2011). Meeting the challenges of educational reform through spatial design in the twenty-first century. Thesis.

Alsweel, R. (n.d.). Education and the role of women in saudi arabia. Thesis

Alturki, N., \& Braswell, R. (2010). Businesswomen in Saudi Arabia: Characteristics, challenges, and aspirations in a regional context. Monitor Group. Retrieved on, 11(19), 12.

Brief Report on the Ninth Development Plan. (2010). 
Cramer, J. P. (2006). Scenarios shaping the next architect's success. Scenarios shaping the next architect's success - designintelligence. Retrieved from www.worlddesignforum.com:http://www.worlddesignforum.com/articles/scenarios -shaping-the-next-architects-success

Danish, A. Y., \& Smith, H. L. (2012). Female entrepreneurship in Saudi Arabia: Opportunities and challenges. International Journal of Gender and Entrepreneurship, 4(3), 216-235. doi:10.1108/17566261211264136

Danko, S. (2010). On designing change. Journal of Interior Design, 36(1), v-ix.

Elamin, A. M., \& Omair, K. (2010). Males' attitudes towards working females in saudi arabia. Personnel Review, 39(6), 746-766. doi:10.1108/0048348101107559.

Fact Book: Saudi Arabia. (n.d.). Fact book: Saudi Arabia. [Web page]. Retrieved from https://www.cia.gov/library/ publications/the-world-factbook/geos/sa.html.

Kirkpatrick, B. L., Kirkpatrick, J. M., \& Freed, P. C. (2007). AutoCAD 2009 for interior design and space planning. Pearson Prentice Hall.

Le Renard, A. (2008). Only for women:" Women, the state, and reform in Saudi Arabia. The Middle East Journal, 62(4), 610-629.

Levins, K. E. (2006). The impact of creativity on the evaluation of entry-level interior design portfolios: Examining the relationships among creative novelty, resolution, and style. Thesis.

Maximizing the Employment of Saudi Females. (2012). Maximizing the employment of saudi females. Oxford strategic consulting. Retrieved from www.employingwomen.com

MENA_Gender_Compendium-2009-1.pdf. (n. d.).

Minkus-McKenna, D. (2009). Women entrepreneurs in Riyadh Saudi, Arabia.

Omair, K. 2008. Women in management in the Arab context. Education, Business and Society: Contemporary Middle Eastern Issues 1: 107-23

Sasaki, S. D. (2004). Designer education: The professional development of interior designers. Ottawa: National Library of Canada $=$ Bibliothèque nationale du Canada.

Smith, S. R., \& Hamon R. H. (2012). Exploring Family Theories. New york, Newyork: Oxford University Press, Inc. 
Sullivan, K. (2012, November 13). Saudi Arabia struggles to employ its mosteducated women. The Independent. Retrieved from http://www.independent.co.uk/news/world/middle-east/saudi-arabia- strugglesto- employ-its-mosteducated-women-8312035.html.

Tarver, E. M. (2013). What I wish I knew: Interior design graduates sense of preparedness to practice. Electronic Thesis.

Vaid, I. Y. (2013). Survey of computer aided design software users in Jeddah, the Kingdom of Saudi Arabia: A case study. Stud, 2(3).

Vaid. (2011). Saudi women and entrepreneurship: Opportunities in architecture and interior design: Bright future for new graduates. Middle East Studies Online Journal, 3(6). Retrieved from Google Scholar.

What Employers Are Looking for. (2012). What employers are looking for. American Society of Interior Designers.

White, J.W., \& Klein, D.M. (2008). Family theories. Los Angeles: Sage Publications. 
APPENDIX A

INFORMED CONSENT FORM (BACK TRANSLATED) (ENGLISH) 


\section{Dear Design Firm,}

I am Najah Alsaffaf a Master's student under the supervision of Professor Connie Dyar in the Master's of Interior and Environmental design program at Illinois State University. I am conducting a research to help understand how to run Interior design companies in Saudi Arabia, and the obstacles that Saudi Arabian women face in order to find jobs in the interior design field. The purpose of this research is to find the factors that enable interior design companies to work to the fullest. It will also reveal the types of opportunities and technologies that are currently available in the field of interior design.

I am inviting your firm to participate in this study. Your firm is suitable to be part of this important research, and will help in providing important information about the design field and enable women to be part of the interior design world. This study will identify the required qualities to manage an interior design firm, which is divided into two sections for women and men. This study will help understand the state of the design field in Saudi Arabia and will expose the image of Saudi's culture in the field of design to the world.

Your participation involves answering an online survey. There are two types of questions: short answers or explanatory, and you have the option of answering either an Arabic or an English version of the survey. The survey consists of 18 questions and will take approximately 20 minutes to complete. Your participation is voluntary and you have the right to withdraw from participating at any time. The time required to gather the information needed for the research is 2 weeks maximum.

Please note that this study will be conducted under the approval of the Institutional Review Board at Illinois State University. All data will remain confidential and secured in the possession of the Department of Family and Consumer science at Illinois State University. For confidentiality code identifiers will be used to mask all gathered information. All the information will be carefully disposed of in a proper manner that will not harm the firm or its employees. The data will be saved on the computers for 15 months only, and then will be deleted.

Saudi Arabia has been a big advocate of education and work opportunities for women to be part of working force. This is evident in the Ninth Development Plan, one of its the major implementations goals is to "promote the effective participation of Saudi women in the kingdom's development" and "providing support to Small and Medium Enterprises and remove obstacles hindering their development". The Ninth Development Plan is a continuation of the developmental approach adopted by the Kingdom throughout the past four decades (2010-2014). "This approach combines the directive planning of government activity and indicative planning of private activity within a framework of developmental paths and the future vision defined by the long-term strategic planning."(Ministry of economy and planning, 2010)

It is important to conduct research in the design field because new and existing firms are in constant search for answers and solutions to ensure that their firms work to their 
fullest. The results will be presented to the interior design journal, and the international journal of Gender and Entrepreneurship, in order to participate in the design community. Regardless of the results, awareness about the needs of interior design firms and the opportunities existing for them in the Saudi market will increase.

Your participation is completely voluntary. There is no penalty for deciding not to participate and you have the right to withdraw at any time for any reason. If you have any questions about the research or your rights as a participant contact the researchers Najah Alsaffaf at naalsaf@ilstu.edu (+1) 217-979-2421 or Connie Dyar at cgarbed@ilstu.edu (+1) 309-438-8007 or the office of Research Ethics \& Compliance at rec@ilstu.edu (+1) 309-438-2529.

Please click on one of the following options

I agree to participate in this survey

I do not agree to participate in this survey 
APPENDIX B

SURVEY QUESTIONS (SURVEY MONKEY FORMAT) (BACK TRANSLATED)

(ENGLISH) 
1. Where is your design firm located?

- Commercial area

- Residential area

- Other, please specify

2. Are you?

- Designer (engineer)

- Firm owner

- Manager of the Design Department

- Firm owner and manager of the Design Department

- Other, please specify

3. What is your gender?

- Male

- Female

4. Your age range?

- Below 24

- 24 to 34

- 35 to 45

- 46 to 56

- 57 to 67

- Above 68

5. Explain your qualifications:

- University name

- Degree obtained

- University specialization

- Country/city

6. Number of designers/engineers working currently at your firm?

- Number of females

- Number of males

- Number of free lancers that are out sourced 
7. What goes into the hiring process of designers?

- Degree obtained

- Experience

- Portfolio

Which of the above and why?

As mentioned before, Saudi Arabia has been a big advocate of education and work opportunities for women to be part of the working force. This is evident in the Ninth Development Plan, one of its the major implementations goals is to "promote the effective participation of Saudi women in the kingdom" and " providing support to Small and Medium Enterprises and removing obstacles hindering their development". The Ninth Development Plan is a continuation of the developmental approach adopted by the Kingdom throughout the past four decades (2010-2014).

The following questions address how design firms are currently operating in relationship to the overall goal of the development plan.

8. Do you offer different types of employment options, such as full-time or parttime? Yes, no

If yes, please list all types of employment that you offer.

9. How do the female employees obtain transportation to and from work?

Please list all the options that are currently available.

10. What options for transportation do you think would be most beneficial to your female employees and hence your business?

11. Are there separate main entrances for both male and female employees?

12. Are there separate working sections within the firm for male and female employees?

- Yes

- No

13. If number (11) is yes, how do female and male sections collaborate to complete projects? For example, in the meeting room, through telecommunications.

14. If number (11) is no, how do designers collaborate at the firm to complete projects? Who manages them? 
15. What software do the designers use to complete their projects? For example: AutoCAD, Revit, 3Dmax.

16. How did the employees acquire the needed skills to become designers? Please put a tick next to all that applies:

- A 4 year Bachelor Degree

- Online training

- Workshops

- Company training

17. Please explain all the ways the designers developed their skills.

18. The field of design especially interior design is developing and prospering in Saudi Arabia, what do you think is the main factor that plays a role in this current exposure, and what do you think of the future and direction of the Interior Design field in Saudi Arabia? 